\title{
Norepinephrine but not Serotonin Reuptake Inhibitors Enhance Theta and Gamma Activity of the Septo-Hippocampal System
}

\author{
Mihály Hajós*,', William E Hoffmann', Deborah D Robinson², Jen H Yu² and Éva Hajós-Korcsok ${ }^{2}$ \\ 'Neurobiology, Pharmacia Corporation, Kalamazoo, MI, USA; ${ }^{2}$ Pharmacology, Pharmacia Corporation, Kalamazoo, MI, USA
}

\begin{abstract}
Current neurobiological concepts attribute a central role of the hippocampal formation in cognitive and affective processes. Recent studies indicate that the hippocampus is affected in human depression, and antidepressant drugs induce hippocampal adaptive changes that are thought to be associated with their therapeutic action. In the present study, we investigated the action of various antidepressant drugs on the activity of the septo-hippocampal system, its oscillatory activity in particular. The acute effects of the norepinephrine (NE) reuptake inhibitors reboxetine and desipramine, and the selective serotonin reuptake inhibitor fluvoxamine were evaluated. Extracellular single-unit recordings were performed from the medial septum/diagonal band of Broca (MS/DBv), with simultaneous hippocampal EEG recordings of anesthetized rats. Systemic administration of reboxetine synchronized hippocampal EEG, resulting in a significant increase in power at theta frequency, and an increase in frequency and power of gamma-wave activity. Parallel to EEG synchrony, reboxetine induced or enhanced theta oscillation of MS/DBv neurons. Oscillatory frequencies of MS/DBv neurons were identical, and phase locked to the corresponding hippocamapal theta frequencies. Under the same experimental conditions, reboxetine induced a two-fold increase in extracellular NE (but not serotonin) levels in the hippocampus as revealed by microdialysis. Desipramine, but not the serotonin reuptake inhibitor fluvoxamine, evoked responses similar to those of reboxetine regarding septo-hippocampal theta activity. The present findings indicate that even though both NE and serotonin reuptake inhibitors are clinically effective antidepressant drugs, their action on the septo-hippocampal oscillatory behavior is different. It is presumed that selective NE reuptake inhibitors could modulate various cognitive processes associated with hippocampal oscillatory activity.

Neuropsychopharmacology (2003) 28, 857-864, advance online publication, 12 March 2003; doi: I 0. I038/sj.npp. I 300 I I6
\end{abstract}

Keywords: norepinephrine; reboxetine; septum; hippocampus; theta; gamma

\section{INTRODUCTION}

Anatomical and functional studies have revealed a central role of the hippocampal formation in various physiological mechanisms related to cognitive and affective processes (Kandel, 2001). These observations are corroborated by clinical evidence, linking cognitive and memory impairment to structural and functional changes in the hippocampal formation (Deweer et al, 2001; Heckers, 2001). Recent studies have also indicated that the hippocampal formation is affected in human depression (Sapolsky, 2000; Nestler et $a l, 2002$ ), as well as in animal models of depression (Czeh et $a l, 2001)$. It has been reported that major depression is associated with atrophy of the hippocampus, resulting in a significant volume loss (Sheline et al, 1996, 1999; Bremner et al, 2000), which might explain some of the well-

\footnotetext{
*Correspondence: M Hajós, Neurobiology, Pharmacia Corporation, 301 Henrietta Street, Kalamazoo, Ml 49007, USA, Tel: + I 616833 7847; Fax: + I 616833 2525, E-mail: mihaly.hajos@pharmacia.com Received 12 September 2002; revised 16 October 2002; accepted 14 November 2002

Online publication: 22 November 2002 at http: //www.acnp.org/ citations/Npp | 12202432
}

documented cognitive deficits that accompany major depression.

Changes in hippocampal formation in response to antidepressant treatment have also attracted great interest. The vast majority of presently available and clinically effective antidepressant drugs act via presynaptic uptake transporters of biogenic amines, such as the selective serotonin reuptake inhibitors (eg fluvoxamine, citalopram, paroxetine) or norepinephrine (NE) reuptake inhibitors (eg desipramine, reboxetine). While their acute mechanism of action is well established, it is now recognized that gradually developing adaptive changes downstream to enhanced serotonin and NE neurotransmission are likely to mediate their therapeutic action (Holsboer, 2001; Nestler, 2002). These adaptive changes range from modulation of intracellular signalling cascade to changes in gene expression. In addition, electrophysiological studies revealed modulating effects of chronic antidepressants treatment on the activity of individual hippocampal neurons (Haddjeri et al, 1998; Bijak et al, 2001); however, the effect of these drugs on the oscillatory activity of the hippocampal formation has not been studied.

Based on experimental observations in rats, theta oscillation of the hippocampal formation is commonly 
regarded as a physiological encoding frequency in memory formation (Buzsaki, 2002; Jensen and Tesche, 2002; Seager et al, 2002). In addition, recent observation of human theta has strengthened the connection between theta oscillation and cognitive processes. Intracranial recordings from human cortex have revealed evidence of high-amplitude theta oscillations throughout the brain, including the neocortex, and its occurrence during working memory tasks (Raghavachari et al, 2001). Given the critical role of the septohippocampal system in cognitive processing, we have investigated the acute actions of the novel antidepressant drug reboxetine, a selective NE reuptake inhibitor, on the neuronal activity of the septo-hippocampal system. In comparison, the effects of the tricyclic NE reuptake inhibitor desipramine and the selective serotonin reuptake inhibitor fluvoxamine were also evaluated.

Simultaneous septal single unit and hippocampal EEG recordings were carried out from anesthetized rats. In addition to theta-frequency analysis, hippocampal gammawave activity was also evaluated since theta- and gammafrequency oscillations of hippocampal electroencephalography (EEG) are closely correlated. gamma oscillation is superimposed on theta activity (Bragin et al, 1995), and both oscillations are thought to occur in similar physiological conditions and be associated with cognitive functions (Gross and Gotman, 1999; Whittington et al, 2000; Orban et al, 2001). In addition, hippocampal NE and serotonin levels have been monitored by microdialysis, paralleling electrophysiological experiments, in order to demonstrate the effect of reboxetine on hippocampal neurotransmitter levels.

\section{MATERIALS AND METHODS}

\section{Animals}

All studies were conducted with male Sprague-Dawley rats (270-300 g, Harlan, Indianapolis). Animals were housed in groups of 5-6, kept under conditions of controlled temperature $\left(21 \pm 1^{\circ} \mathrm{C}\right)$ and lighting (lights on 06.00 $18.00 \mathrm{~h}$ ) and were given food pellets and water ad lib. Studies were performed between 8.00 and $17.00 \mathrm{~h}$. All procedures were carried out under an approved animaluse protocol and were in compliance with the Animal Welfare Act Regulations (9 CFR Parts 1-3) and with the 'Guide for the Care and Use of Laboratory Animals' (ILAR, 1996).

\section{Electrophysiological Experiments}

Surgical procedures and drug solutions. Male SpragueDawley rats were anesthetized with chloral hydrate anesthesia $(400 \mathrm{mg} / \mathrm{kg}$, i.p.), and the femoral artery and vein were cannulated for monitoring arterial blood pressure and administration of drugs or additional doses of anesthetic, respectively. The anesthetized rat was placed in a stereotaxic frame, and craniotomy was performed above the regions of the medial septum and unilateral CA1 hippocampus. Body temperature of the rat was maintained at $36-37^{\circ} \mathrm{C}$ by means of an isothermal $\left(37^{\circ} \mathrm{C}\right)$ heating pad (Braintree Scientific, Braintree, MA). Reboxetine, a racemic mixture of RR- and SS-([2-[a[2-ethoxyphenoxy]benzyl]-morpholine sulphonate]), synthesized at Pharmacia, Kalamazoo, MI, USA), desipramine hydrochloride (Sigma-Aldrich, St Louis, MO, USA) and fluvoxamine maleate (Solvay Duphar, Weesp, The Netherlands) solutions were made up based upon their salt weights in $\mathrm{H}_{2} \mathrm{O}$ and concentrations adjusted so that injection volumes equalled $1 \mathrm{ml} / \mathrm{kg}$ body weight. Desipramine and fluvoxamine were tested at doses that selectively and effectively inhibit NE and serotonin uptake, respectively (L'Heureux et al, 1986; Jordan et al, 1994; Bosker et al, 1995; Perry and Fuller, 1997; Hajós-Korcsok et al, 2000; Bymaster et al, 2002) to inhibit selectively and effectively either NE or serotonin uptake, respectively. After conclusion of experiments, animals were euthanized with an IV bolus of chloral hydrate. Brains were removed, blocked and frozen on a cryostat stage for histological verification of electrode placements.

Single-unit recordings. Single units were recorded from the medial septum and vertical limb of the diagonal band of Broca (MS/DBv; coordinates: $0.2 \mathrm{~mm}$ anterior to bregma, lateral $0 \mathrm{~mm}$ and $5-7 \mathrm{~mm}$ below the dura; Paxinos and Watson, 1986) using glass microelectrodes filled with $2 \mathrm{M} \mathrm{NaCl}$ (impedance 10-20 M $\Omega$ ). Extracellularly recorded potentials were amplified, filtered, displayed, discriminated and recorded for off-line analysis using conventional electrophysiological methods (Hajós et al, 1998). Neuronal activity was followed by constructing firing rate, frequency and interspike interval histograms using Spike3 program (Cambridge Electronic Design, Cambridge, UK). Oscillation of neuronal activity was analyzed by autocorrelation. Location of the recording electrode was marked with iontophoretic ejection of Pontamine Sky Blue and revealed by routine histological procedure. Only neurones located within the $\mathrm{MS} / \mathrm{DBv}$ are included in the study.

EEG recording. Unilateral hippocampal field potential (EEG) was recorded by a metal monopolar macroelectrode placed into the CA1 region (coordinates: $3.0 \mathrm{~mm}$ posterior from the bregma, $2.0 \mathrm{~mm}$ lateral and $3.8 \mathrm{~mm}$ ventral; Paxinos and Watson, 1986). Field potentials were amplified, filtered $(0.1-100 \mathrm{~Hz})$, displayed, and recorded for on-line and off-line analysis (Spike3 program; Cambridge Electronic Design, Cambridge, UK). Rhythmic synchronized (theta) and large amplitude irregular hippocampal activities were distinguished in the EEG; quantitative EEG analysis was performed by means of fast Fourier transformation (Krause et al, 2003). Power spectrum density of EEG for theta activity was calculated at a peak frequency between 3 and $6 \mathrm{~Hz}$. For gamma-wave activity, hippocampal EEG activity was band-pass filtered between 32 and $48 \mathrm{~Hz}$ with a transition gap of $22 \mathrm{~Hz}$ and analyzed off-line by fast Fourier transformation. Location of the recording electrode was verified histologically.

Data analysis and statistics. Mean firing rates were determined in periods of 100-300 s before and after drug treatment. Interspike interval histograms, autocorrelograms, and hippocampal EEG power spectra were determined in periods of $100-300 \mathrm{~s}$, but for an identical duration preceding and following drug treatment. Differences between baseline and drug treatment were assessed by paired Student's $t$-test. 


\section{Microdialysis Experiments}

Surgery. Rats were anesthetized with chloral hydrate $(400 \mathrm{mg} / \mathrm{kg}$, i.p.). The femoral vein was cannulated for drug administration. Microdialysis probes ( $2 \mathrm{~mm}$ tip length, CMA) were implanted as described previously (Hajós-Korcsok, 2000). Stereotaxic coordinates for the final microdialysis probe placement in the dorsal hippocampus were: rostrocaudal $-3.8 \mathrm{~mm}$, medio-lateral $-2.0 \mathrm{~mm}$, dorso-ventral $-4.0 \mathrm{~mm}$, from bregma and dura surface (Paxinos, 1986).

Microdialysis procedure. Probes were perfused continuously $(2 \mu \mathrm{l} / \mathrm{min})$ with artificial cerebrospinal fluid (aCSF) for $60 \mathrm{~min}$ before the start of sample collection. The composition of aCSF solution was: $145 \mathrm{mM} \mathrm{NaCl}, 2.7 \mathrm{mM} \mathrm{KCl}, 1 \mathrm{mM}$ $\mathrm{MgCl}_{2}, 2 \mathrm{mM} \mathrm{Na} \mathrm{NPOO}_{4}$, and $1.2 \mathrm{mM} \mathrm{CaCl}$ (pH 7.4). Perfusates were collected every $10 \mathrm{~min}$ using a refrigerated fraction collector (BAS HoneyComb) into glass vials containing $5 \mu \mathrm{l}$ of $0.01 \mathrm{~N}$ perchloric acid and $2.5 \mu \mathrm{l}$ of $1 \mathrm{mM}$ EDTA (total volume of $27.5 \mu \mathrm{l}$ ). Samples were analyzed for $\mathrm{NE}$ and serotonin on a high-pressure liquid chromatography (HPLC) assay. After establishing stable basal levels of NE and serotonin (about $2 \mathrm{~h}$ after commencing perfusion), racemic reboxetine $(0.3 \mathrm{mg} / \mathrm{kg})$ was injected intravenously (at $1 \mathrm{ml} / \mathrm{kg}$ volume) and washed in with $0.3 \mathrm{ml}$ saline vehicle. The IV cannula was regularly flushed with $0.9 \%$ saline solution (containing $25 \mathrm{IU}$ heparin $/ \mathrm{ml}$ ). The depth of anesthesia was constantly monitored and supplementary doses of chloral hydrate $(10 \mathrm{mg} / \mathrm{kg})$ were given via the cannula as necessary. Care has been taken to avoid injection of chloral hydrate within the same 10-min sample as reboxetine. Microdialysate samples were collected for a further $60 \mathrm{~min}$.

Measurement of dialysate serotonin and NE. Perfusate samples were analyzed for serotonin and NE using HPLC with electrochemical detection (EC). Samples $(20 \mu \mathrm{l})$ were injected by an ESA 542 refrigerated autosampler onto a Hyperosil ODS $\mathrm{C}_{18}$ column $(4.6 \mathrm{ID} \times 150 \mathrm{~mm}, 3 \mu \mathrm{m}$ particles, $40^{\circ} \mathrm{C}$ column temperature) perfused by ESA Model 582 HPLC pump at a rate of $0.55 \mathrm{ml} / \mathrm{min}$ with a mobile phase comprising $75 \mathrm{mM} \mathrm{NaH} \mathrm{H}_{2} \mathrm{PO}_{4}, 1.8 \mathrm{mM}$ sodium octane sulfonate, $25 \mu \mathrm{M}$ EDTA, and $10 \%$ (v/v) methanol (final pH 3.0). Samples were analyzed by an ESA Coulochem II 5200A electrochemical detector with an ESA 5041 highsensitivity analytical cell and an ESA 5020 guard cell. Electrochemical detection was performed at $220 \mathrm{mV}$ with the guard cell at $350 \mathrm{mV}$.

Data analysis. Data are presented as \% of basal NE and serotonin levels determined in dialysate samples (not corrected for membrane recovery). The effect of reboxetine on NE and serotonin was analyzed using one-way ANOVA with repeated measures. Post hoc comparisons within group were made using the protected least significant difference (PLSD) test.

\section{RESULTS}

\section{Septo-hippocampal Electrophysiology}

Single-unit activity of $M S / D B v$. Individual MS/DBv neurons, recorded from anesthetized rats, displayed a con- siderable variability in their firing activity and firing pattern. The mean firing rate of $\mathrm{MS} / \mathrm{DBv}$ neurons was $14.6 \pm 2.8$ spikes/s $(n=28)$, ranging from 1.7 to 45 spikes/s. Systemic (IV) administration of the tested monoamine reuptake inhibitors did not significantly influence the firing rate activity of $\mathrm{MS} / \mathrm{DBv}$ neurons at any of the tested doses. Thus, firing rates of MS/DBv neurons were $15.0 \pm 3.4$ and $15.0 \pm 4.3$ spikes/s following cumulative doses of 0.3 and $1.0 \mathrm{mg} / \mathrm{kg}$ reboxetine $(n=8)$, respectively, and $19.5 \pm 6.9$ spikes/s after administration of $1 \mathrm{mg} / \mathrm{kg}$ desipramine $(n=7)$. Administration of fluvoxamine at cumulative doses of 1.0 and $3.0 \mathrm{mg} / \mathrm{kg}(n=6)$ resulted in $11.4 \pm 3.0$ and $13.2 \pm 4.3$ spikes/s mean firing rates, respectively, and in $14.2 \pm 4.3$ spikes $/ \mathrm{s}$ after $10 \mathrm{mg} / \mathrm{kg}(n=7)$. In addition to firing rate activity, changes in firing pattern and oscillatory activity of $\mathrm{MS} / \mathrm{DBv}$ neurons were analyzed by constructing autocorrelation histograms. The selective NE reuptake inhibitor reboxetine $(0.3-1 \mathrm{mg} / \mathrm{kg})$ or despiramine $(1 \mathrm{mg} /$ $\mathrm{kg}$ ) induced or enhanced a long-lasting (measured up to $30 \mathrm{~min}$ ) oscillation of MS/DBv neurons (Figures 1 and 2). In contrast, the selective serotonin reuptake inhibitor fluvoxamine $(1-10 \mathrm{mg} / \mathrm{kg})$ failed to alter the firing pattern or oscillatory activity of MS/DBv neurons (Figure 3).

Hippocampal EEG activity. Simultaneous recordings of $\mathrm{MS} / \mathrm{DBv}$ neuronal activity with hippocampal CA1 field potential revealed an association between MS/DBv neuronal oscillation and hippocampal EEG activity, as it has been described previously (Ford et al, 1989; Vertes and Kocsis, 1997). Thus, it was found that parallel to changes of oscillatory activity of $\mathrm{MS} / \mathrm{DBv}$ neurons, reboxetine also synchronized hippocampal EEG activity at theta frequency (Figure 1). The tricyclic NE reuptake inhibitor desipramine $(1 \mathrm{mg} / \mathrm{kg})$ (Figure 2) induced a similar synchronous hippocampal activity (Furthermore, oscillation of simultaneously recorded $\mathrm{MS} / \mathrm{DBv}$ neurons was phase locked to hippocampal theta activity, and oscillated at the corresponding hippocampal frequency. Quantitative EEG analyses using fast Fourier transformation revealed that reboxetine $(0.3-1 \mathrm{mg} / \mathrm{kg})$ significantly increased the power of hippocampal EEG at peak theta frequency, the minimal significantly effective dose being $0.3 \mathrm{mg} / \mathrm{kg}$ (Figure 1; Table 1 ). Peak theta frequency was not altered by reboxetine significantly (Table 1). In addition, reboxetine significantly increased both the power and frequency of EEG activity in the gamma-frequency $(28-48 \mathrm{~Hz})$ range (Table 1). The tricyclic NE reuptake inhibitor desipramine $(1 \mathrm{mg} / \mathrm{kg}, n=7)$ significantly increased theta power and, in tendency, increased gamma power $(P<0.1)$. Desipramine did not alter hippocampal theta or gamma peak frequencies (Table 1). In contrast, fluvoxamine $(1-10 \mathrm{mg} / \mathrm{kg}, n=13)$ failed to alter hippocampal EEG activity/power either at theta- or gamma-frequency range (Figure 3, Table 1).

\section{Microdialysis Experiments}

Basal dialysate $\mathrm{NE}$ and serotonin levels in the dorsal hippocampus of anesthetized rats were $0.19 \pm 0.06$ and $0.28 \pm 0.07 \mathrm{fmol} / \mu \mathrm{l}(n=6)$, respectively. Time-course effect of intravenously administered reboxetine $(0.3 \mathrm{mg} / \mathrm{kg})$ on extracellular NE and serotonin levels is shown in Figure 4. Reboxetine caused a marked and long-lasting increase in 
Control
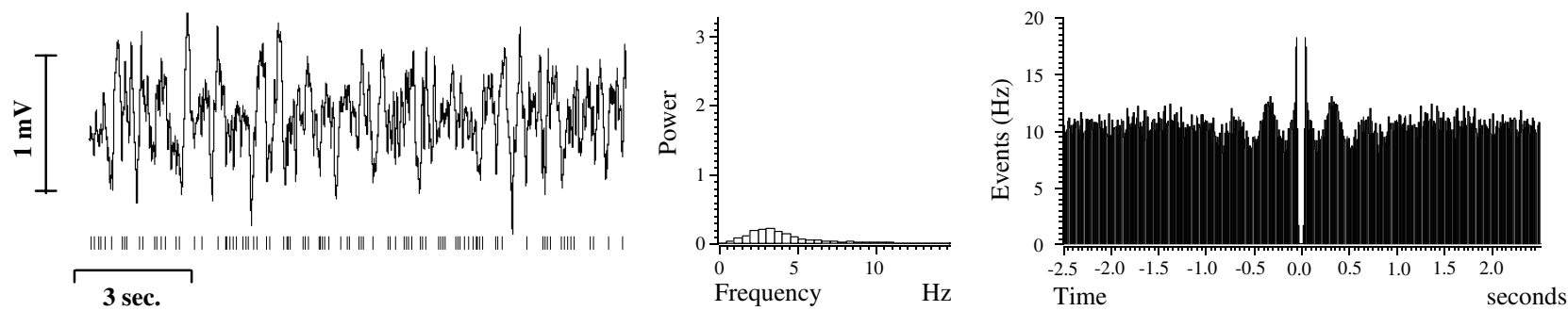

Reboxetine $(0.3 \mathrm{mg} / \mathrm{kg}, \mathrm{IV})$
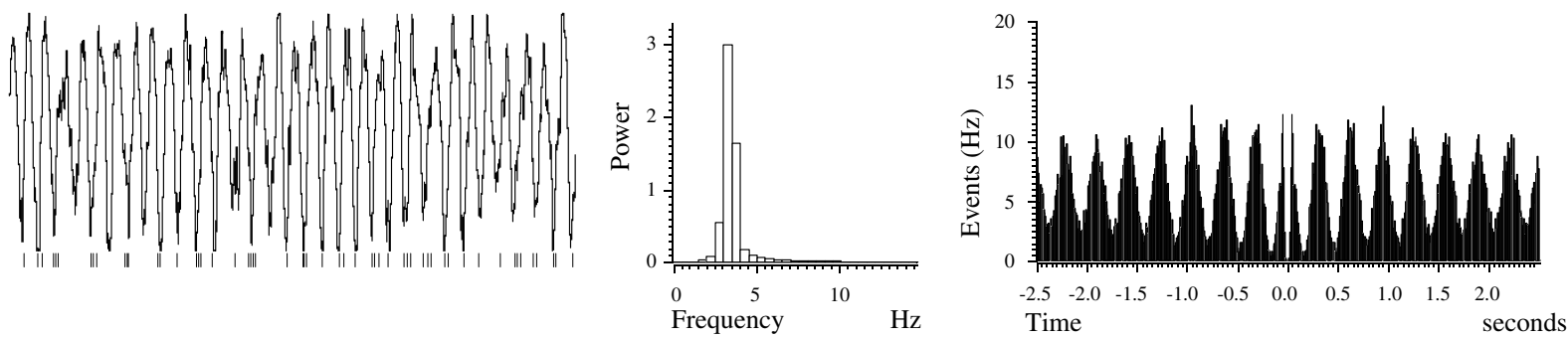

Figure I Typical recording showing theta activity of the septo-hippocampal system induced by systemic administration of reboxetine. Left columns show periods of simultaneously recorded hippocampal EEG (upper trace) and firing activity of MS/DBv neuron (lower trace) during control baseline period (control), and after administration of reboxetine. Columns in the middle and the right show power spectra $\left(\mu \mathrm{V}^{2} / 0.5 \mathrm{~Hz}\right.$ ) of the hippocampal EEG (using fast Fourier transformation), and oscillation of the MS/DBv neuron (autocorrelation), respectively. Voltage calibration corresponds to hipppocampal EEG.
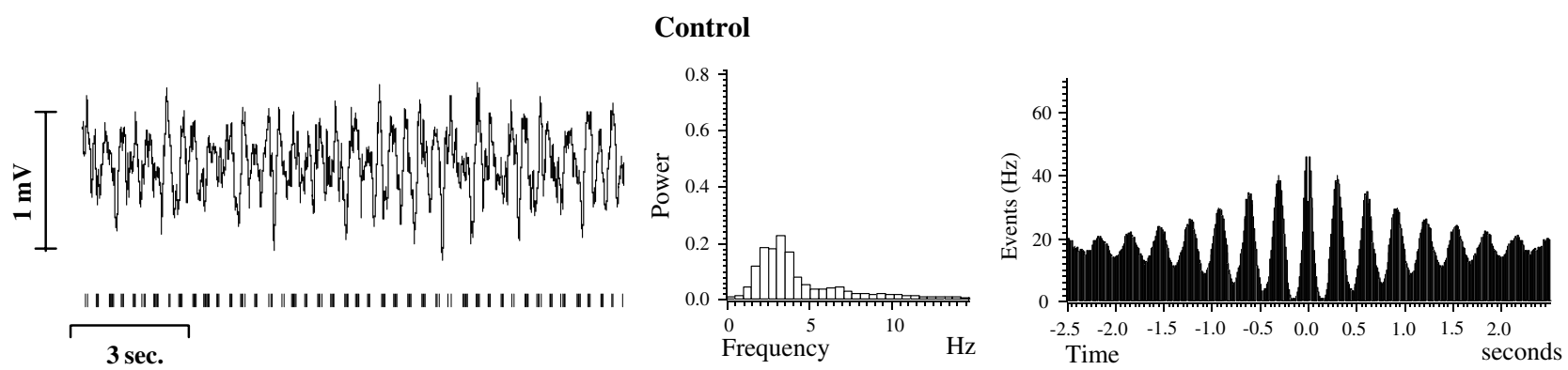

Desipramine (1.0 mg/kg, IV)

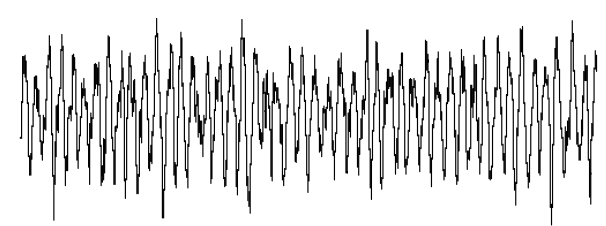

| | | | | | | | | | | | | | | | | | | | | | | | || | | | | | | | | | | | | | | | | | | | | | | | | | | | | | | | | | | | ||
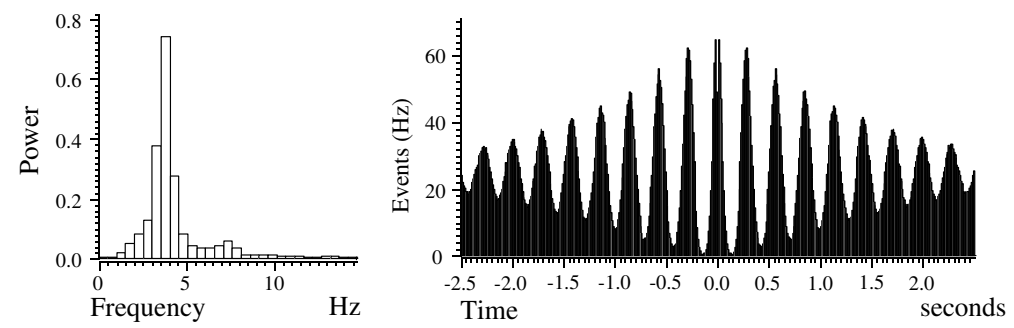

Figure 2 Typical recording showing theta activity of the septo-hippocampal system induced by systemic administration of desipramine. Left columns show periods of simultaneously recorded hippocampal EEG (upper trace) and firing activity of MS/DBv neuron (lower trace) during control baseline period (control), and after administration of desipramine. Columns in the middle and the right show power spectra $\left(\mu \mathrm{V}^{2} / 0.5 \mathrm{~Hz}\right)$ of the hippocampal EEG, and oscillation of the MS/DBv neuron, respectively.

dialysate NE levels, reaching a maximum increase of $220 \%$ of basal levels in the second sample $(20 \mathrm{~min})$ following drug administration. Statistical analysis of the data (one-way ANOVA) showed a significant overall effect of reboxetine on NE $\left(F_{(11,75)}=2.95, P<0.003\right)$. Post hoc analysis (PLSDtest) revealed that dialysate $\mathrm{NE}$ levels were significantly different from basal NE levels at S8, S9, S10, and S11 time points. In the same group of animals, dialysate serotonin levels were not significantly altered following systemic reboxetine administration (Figure 4). Statistical analysis of the data (one-way ANOVA) showed no effect of reboxetine on serotonin $\left(\mathrm{F}_{(11,76)}=0.85, P=0.59, \mathrm{NS}\right)$.

\section{DISCUSSION}

The present findings demonstrate that acute administration of NE reuptake inhibitors reboxetine and desipramine induces and enhances synchronized theta activity of the 
Control
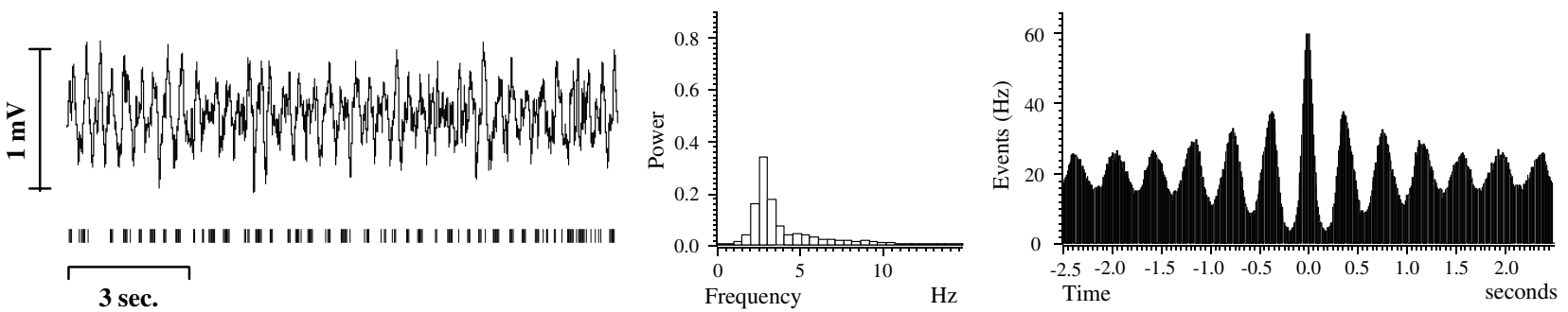

Fluvoxamine $(3.0 \mathrm{mg} / \mathrm{kg}, \mathrm{IV})$

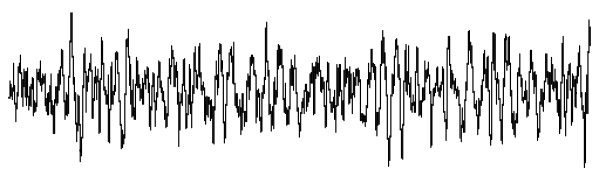

| || | | | | | | | | | | | || | || || || | | | | | | || || || | || | || || || || || || || || | || || | || | ||
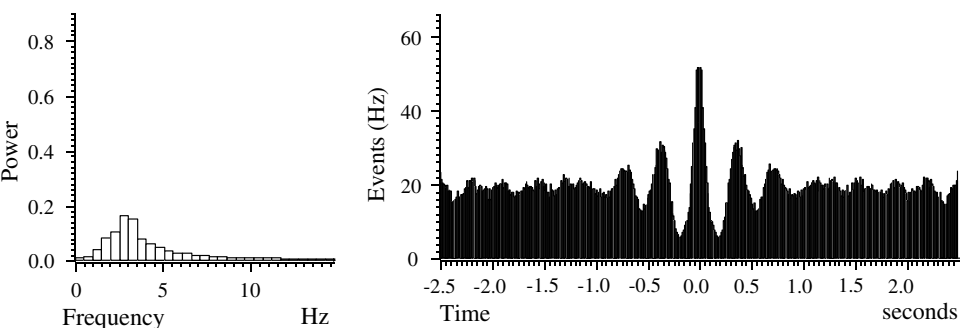

Figure 3 Typical recording showing the effects of systemic administration of fluvoxamine on septo-hippocampal activity. Left columns show periods of simultaneously recorded hippocampal EEG (upper trace) and firing activity of MS/DBv neuron (lower trace) during control baseline period (control), and after administration of fluvoxamine. Columns in the middle and the right show power spectra $\left(\mu \mathrm{V}^{2} / 0.5 \mathrm{~Hz}\right)$ of the hippocampal EEG, and oscillation of the MS/DBv neuron, respectively.

Table I Effects of IV Administration of Reboxetine, Desiparmine, and Fluvoxamine (Doses Indicated in Parentheses) on Hippocampal EEG as Revealed by Fast Fourier Transformation (Mean \pm SEM)

\begin{tabular}{|c|c|c|c|c|}
\hline $\begin{array}{l}\text { Treatment } \\
\text { (mg/kg, i.v.) }\end{array}$ & $\begin{array}{c}\text { Theta Power } \\
\left(\mu V^{2} / 0.5 \mathrm{~Hz} \times 10^{2}\right)\end{array}$ & $\begin{array}{c}\text { Theta Frequency } \\
(\mathrm{Hz})\end{array}$ & $\begin{array}{c}\text { Gamma Power } \\
\left(\mu V^{2} / 0.5 \mathrm{~Hz} \times 10\right)\end{array}$ & $\begin{array}{c}\text { Gamma } \\
\text { Frequency }(\mathrm{Hz})\end{array}$ \\
\hline \multicolumn{5}{|l|}{ Reboxetine $(n=8)$} \\
\hline $\begin{array}{l}\text { Control } \\
\text { Reboxetine (0.3) }\end{array}$ & $\begin{array}{c}18 \pm 4 \\
104 \pm 40 *\end{array}$ & $\begin{array}{l}3.6 \pm 0.2 \\
3.7 \pm 0.2\end{array}$ & $\begin{array}{l}23 \pm 2.5 \\
37 \pm 5.7^{*}\end{array}$ & $\begin{array}{l}27.5 \pm 0.7 \\
29.3 \pm 0.7 *\end{array}$ \\
\hline \multicolumn{5}{|l|}{ Desipramine $(n=7)$} \\
\hline $\begin{array}{l}\text { Control } \\
\text { Desipramine (I.0) }\end{array}$ & $\begin{array}{l}22 \pm 6 \\
65 \pm 25^{*}\end{array}$ & $\begin{array}{l}3.4 \pm 0.7 \\
4.5 \pm 0.2\end{array}$ & $\begin{array}{l}25 \pm 3.5 \\
37 \pm 9.6\end{array}$ & $\begin{array}{l}28.3 \pm 0.3 \\
29.1 \pm 0.6\end{array}$ \\
\hline \multicolumn{5}{|l|}{ Fluvoxamine } \\
\hline $\begin{array}{l}\text { Control }(n=6) \\
\text { Fluvoxamine }(3.0)\end{array}$ & $\begin{array}{l}19 \pm 4 \\
33 \pm 14\end{array}$ & $\begin{array}{l}3.4 \pm 0.2 \\
3.5 \pm 0.2\end{array}$ & $\begin{array}{l}27 \pm 10 \\
28 \pm 7.1\end{array}$ & $\begin{array}{l}29.0 \pm 0.7 \\
30.0 \pm 0.6\end{array}$ \\
\hline $\begin{array}{l}\text { Control }(n=7) \\
\text { Fluvoxamine }(10.0)\end{array}$ & $\begin{array}{l}23 \pm 10 \\
17 \pm 5\end{array}$ & $\begin{array}{l}3.6 \pm 0.3 \\
3.6 \pm 0.1\end{array}$ & $\begin{array}{l}29 \pm 9.3 \\
38 \pm 16\end{array}$ & $\begin{array}{l}29.4 \pm 0.5 \\
29.9 \pm 0.4\end{array}$ \\
\hline
\end{tabular}

Theta and gamma powers were calculated at peak frequencies. $* P<0.05$, paired $t$-test.

septo-hippocampal system. Both reboxetine and desipramine evoked theta oscillation of medial septal neurons, and increased power of theta-wave activity of hippocampal EEG. In addition, reboxetine increased both the power and frequency of hippocampal gamma activity. In contrast, acute administration of the serotonin reuptake inhibitor fluvoxamine failed to alter activity of the septo-hippocampal system. These data indicate that NE reuptake inhibitors can modulate oscillatory activity of the septo-hippocampal system, thus potentially affecting various functions associated with this limbic circuitry.

Selective actions of fluvoxamine and desipramine on the serotonin and NE transporters, respectively, have been extensively demonstrated using in vivo microdialysis. Thus, acute administration of fluvoxamine, at same doses as tested in the present study, augments extracellular levels of serotonin, but not NE, in various brain regions (Jordan et al, 1994; Bosker et al, 1995; Bymaster et al, 2002). Conversely, the tricyclic antidepressant, desipramine selectively enhances brain extracellular NE, but not serotonin, levels (L'Heureux et al, 1986; Perry and Fuller, 1997; HajósKorcsok et al, 2000). Reflecting its marked and selective activity on the NE transporter (Wong et al, 2000), similar actions of the novel antidepressant drug reboxetine on brain NE levels were reported (Sacchetti et al, 1999; Millan et al, 2001). In the present study, reboxetine, when 


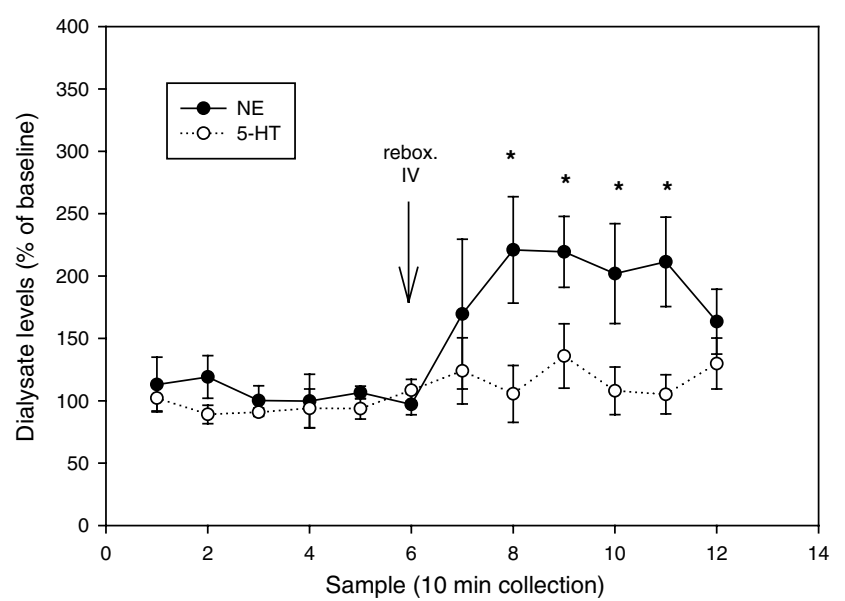

Figure 4 Effect of reboxetine on dialysate NE and serotonin (5-HT) levels in the dorsal hippocampus of anesthetized rats. Reboxetine $(0.3 \mathrm{mg} /$ $\mathrm{kg}$ ) was administered intravenously as indicated by the arrow. Each datapoint is a mean $\pm \operatorname{SEM}(n=6)$. $* P<0.0$ I vs predrug values (one-way ANOVA, post hoc Dunnett's test).

administered in the same dose and route as in the electrophysiological experiments, induced a marked and long-lasting increase in dialysate $\mathrm{NE}$ levels without altering dialysate serotonin levels in the hippocampus. Taken together, the present findings indicate that desipramineand reboxetine-induced facilitation of hippocampal thetawave activity could be contributed to enhanced $\mathrm{NE}$ neurotransmission.

The hippocampal formation and one of its main afferent projection regions, the medial septum/diagonal band of Broca, are heavily innervated by both $\mathrm{NE}$ and serotonin neurons, and it is known that they influence various hippocampal functions, including its oscillatory activity (Vertes and Kocsis, 1997; Berridge, 1998; Leranth and Vertes, 1999). In contrast to the serotonin system, NE neurons play a prominent role in controlling the degree of alertness (Aston-Jones and Bloom, 1981; Aston-Jones et al, 1999) and activation of pontine locus coeruleus NE neurons induces intense theta rhythm in the hippocampus (Berridge and Foote, 1991). The present study further substantiates a prominent role of $\mathrm{NE}$ in hippocampal theta-wave regulation, showing that inhibition of NE reuptake induces or enhances hippocampal theta-wave activity. However, the exact mechanism underlying the hippocampal theta activity evoked by NE reuptake inhibitors cannot be determined from the present studies. Current theories on hippocampal theta-wave regulation attribute a central role for $\mathrm{MS} / \mathrm{DBv}$ projecting GABA neurons (Vertes and Kocsis, 1997; Buzsaki, 2002). In the present study, we showed that NE reuptake inhibitors, concomitantly with an increased hippocampal theta-wave activity, shifted firing pattern of $\mathrm{MS} / \mathrm{DBv}$ neurons into theta oscillation. Oscillatory frequencies of MS/DBv neurons were identical, and phase locked to the corresponding hippocampal theta frequency, as it has been observed at physiological conditions (Vertes and Kocsis, 1997; Buzsaki, 2002). It has been demonstrated that local, intra-MS/DBv application of the adrenergic $\beta$ agonist isoproterenol elicits robust hippocampal theta activity in anesthetized rats (Berridge, 1998); therefore, the NE reuptake inhibitor-induced theta activity could be mediated via the $\mathrm{MS} / \mathrm{DBv}$. Alternatively, an enhanced NE neurotransmission could modulate interactions between $\mathrm{MS} / \mathrm{DBv}$ and hippocampal oscillators, leading to theta oscillation in both the MS/DBv and hippocampus. In contrast to the NE reuptake inhibitors, our results indicate that fluvoxamine, a selective serotonin reuptake inhibitor (Jordan et al, 1994; Bosker et al, 1995), did not induce or enhance hippocampal theta activity and theta oscillation of $\mathrm{MS} / \mathrm{DBv}$ neurons. This observation is in agreement with the previous finding demonstrating a permissive role of serotonin system on theta activity: activation of serotonin neurons blocks and inhibition of serotonin neurons activates both septal and hippocampal theta activity either in anesthetized or unanesthetized, behaving animals (Kinney et al, 1996; Marrosu et al, 1996; Vertes and Kocsis, 1997). Moreover, we have shown recently that 5 -HT2C receptor agonists inhibit, whereas antagonists enhance theta activity of the septo-hippocampal system (Hajós and Hoffmann, 2000).

In the present study, hippocampal field potential recordings also revealed gamma-frequency oscillation under chloral hydrate anesthesia. Parallel to an increase in hippocampal theta activity, reboxetine enhanced power of gamma oscillation, resembling physiological conditions, (either in awake or anesthetized situations), where gamma power is most prominent during the presence of hippocampal theta activity (Bragin et al, 1995; Penttonen et al, 1998). The mean frequency of gamma field oscillation was lower in our anesthetized animals than it was observed in awake, freely moving rats (Bragin et al, 1995), but similar to previously reported values under urethan anesthesia (Penttonen et al, 1998). Reboxetine not only significantly increased power but also the frequency of hippocampal gamma field oscillation. Similar changes were also observed after desipramine administration. The serotonin reuptake inhibitor fluvoxamine not only failed to enhance theta activity, but it did not increase either power or frequency of gamma field activity in the hippocampus, reflecting a close correlation between the two oscillatory activities. Although mechanisms underlying gamma oscillations are not fully understood, hippocampal gamma oscillation is thought to be generated by populations of mutually interconnected inhibitory interneurons (Traub et al, 1996; Whittington et al, 2000; Orban et al, 2001), contributing to an entrained and synchronized activity of excitatory cells at a gammafrequency rhythm. Therefore, it is presumed that NE influences hippocampal gamma oscillation via interaction of GABA interneurons. However, given the anatomical and functional heterogeneity of hippocampal interneurons and their diverse response to NE (Parra et al, 1998), a precise mode of action of NE cannot be determined presently.

In summary, the present findings point to a different role of NE and serotonin in the regulation of septo-hippocampal oscillatory activity: enhanced $\mathrm{NE}$, but not serotonin neurotransmission by antidepressant drugs, initiates septo-hipocampal theta activity. Furthermore, the increased hippocampal theta activity is accompanied by an increased gamma-wave oscillation in the hippocampus. Given the correlation between the septo-hippocampal oscillatory activity and cognitive processes, the presently described action of reboxetine could explain its lack of disrupting cognitive function (Hindmarch, 1998; Tanum, 2000; Siepmann et al, 2001), and its ability to improve cognitive 
disturbances associated with depression (Kasper et al, 2000; Rammsayer et al, 2001; Ferguson et al, 2002). Even though both $\mathrm{NE}$ and serotonin reuptake inhibitors are shown to be clinically effective antidepressant drugs, their acute action on the septo-hippocampal oscillatory behavior is different. Further studies are warranted to determine whether chronic administration of selective $\mathrm{NE}$ and serotonin reuptake inhibitors would differently influence the activity of the septo-hippocampal system.

\section{REFERENCES}

Aston-Jones G, Bloom FE (1981). Activity of norepinephrinecontaining locus coeruleus neurons in behaving rats anticipates fluctuations in the sleep-waking cycle. J Neurosci 1: 876-886.

Aston-Jones G, Rajkowski J, Cohen J (1999). Role of locus coeruleus in attention and behavioral flexibility. Biol Psychiatry 46: $1309-1320$.

Berridge CW (1998). Modulation of forebrain electroencephalographic activity and behavioral state by the locus ceruleusnoradrenergic system: involvement of the medial septal area. Adv Pharmacol 42: 744-748.

Berridge CW, Foote SL (1991). Effects of locus coeruleus activation on electroencephalographic activity in neocortex and hippocampus. J Neurosci 11: 3135-3145.

Bijak M, Zahorodna A, Tokarski K (2001). Opposite effects of antidepressants and corticosterone on the sensitivity of hippocampal CA1 neurons to 5-HT1A and 5-HT4 receptor activation. Naunyn Schmiedebergs Arch Pharmacol 363: 491-498.

Bragin A, Jando G, Nadasdy Z, Hetke J, Wise K, Buzsáki G (1995). Gamma frequency $(40-100 \mathrm{~Hz})$ patterns in the hippocampus of the behaving rat. $J$ Neurosci 15: 47-60.

Bremner JD, Narayan M, Anderson ER, Staib LH, Miller HL, Charney DS (2000). Hippocampal volume reduction in major depression. Am J Psychiatry 157: 115-118.

Bosker FJ, Klompmakers AA, Westenberg HGM (1995). Effects of single and repeated oral administration of fluvoxamine on extracellular serotonin in the median raphe nucleus and dorsal hippocampus of the rat. Neuropharmacology 34: 501-508.

Buzsaki G (2002). Theta oscillations in the hippocampus. Neuron 33: 325-340.

Bymaster FP, Zhang W, Carter PA, Shaw J, Chernet E, Phebus L et al (2002). Fluoxetine, but not other selective serotonin reuptake inhibitors, increases NE and dopamine extracellular levels in the prefrontal cortex. Psychopharmacology 160: 353-361.

Czeh B, Michaelis T, Watanabe T, Frahm J, de Biurrun G, van Kampen $M$ et al (2001). Stress-induced changes in cerebral metabolites, hippocampal volume, and cell proliferation are prevented by antidepressant treatment with tianeptine. Proc Natl Acad Sci USA 98: 12796-12801.

Deweer B, Pillon B, Pochon JB, Dubois B (2001). Is the HM story only a 'remote memory'? Some facts about hippocampus and memory in humans. Behav Brain Res 127: 209-224.

Ferguson JM, Mendels J, Schwartz GE (2002). Effects of reboxetine on Hamilton Depression Rating Scale factors from randomized, placebo-controlled trials in major depression. Int Clin Psychopharmacol 17: 45-51.

Ford RD, Colom LV, Bland BH (1989). The classification of medial septum-diagonal band cells as theta-on or theta-off in relation to hippocampal EEG states. Brain Res 493: 269-282.

Gross DW, Gotman J (1999). Correlation of high-frequency oscillations with the sleep-wake cycle and cognitive activity in humans. Neuroscience 94: 1005-1018.
Haddjeri N, Blier P, de Montigny C (1998). Long-term antidepressant treatments result in a tonic activation of forebrain 5HT1A receptors. J Neurosci 18: 10150-10156.

Hajós M, Hoffmann WE (2000). Regulation of septo-hippocampal activity by $5-\mathrm{HT} 2 \mathrm{C}$ receptors. Soc Neurosci Abstr, Progr No. 690.6 .

Hajós M, Richards CD, Szekely AD, Sharp T (1998). An electrophysiological and neuroanatomical study of the medial prefrontal cortical projection to the midbrain raphe nuclei in the rat. Neuroscience 87: 95-108.

Hajós-Korcsok E, McTavish SF, Sharp T (2000). Effect of a selective 5 -hydroxytryptamine reuptake inhibitor on brain extracellular noradrenaline: microdialysis studies using paroxetine. Eur $J$ Pharmacol 407: 101-107.

Heckers S (2001). Neuroimaging studies of the hippocampus in schizophrenia. Hippocampus 11: 520-528.

Hindmarch I (1998). Effect of antidepressants on cognitive and psychomotor function: the lack of effect of reboxetine. Hum Psychopharmacol Clin 13(Suppl 1): S21-S27; FEB.

Holsboer F (2001). Stress, hypercorticolism and corticosteroid receptors in depression: implications for therapy. J Affect Dis 62: 77-91.

Jensen O, Tesche CD (2002). Frontal theta activity in humans increases with memory load in a working memory task. Eur J Neurosci 15: 1395-1399.

Jordan S, Kramer GL, Zukas PK, Moeller M, Petty F (1994). In vivo biogenic amine efflux in medial prefrontal cortex with imipramine, fluoxetine, and fluvoxamine. Synapse 18: 294-297.

Kandel ER (2001). The molecular biology of memory storage: a dialogue between genes and synapses. Science 294: 1030-1038.

Kasper S, el Giamal N, Hilger E (2000). Reboxetine: the first selective noradrenaline reuptake inhibitor. Expert Opin Pharmacother 1: 771-782.

Kinney GG, Kocsis B, Vertes RP (1996). Medial septal unit firing characteristics following injections of $8-\mathrm{OH}-\mathrm{DPAT}$ into the median raphe nucleus. Brain Res 708: 116-122.

Krause M, Hoffmann WE, Hajós M (2003). Auditory sensory gating in hippocampus and reticular thalamic neurons in anesthetized rats. Biol Psychiatry, in press.

Leranth C, Vertes RP (1999). Median raphe serotonergic innervation of medial septum/diagonal band of broca (MSDB) parvalbumin-containing neurons: possible involvement of the MSDB in the desynchronization of the hippocampal EEG. $J$ Comp Neurol 410: 586-598.

L'Heureux R, Dennis T, Curet O, Scatton B (1986). Measurement of endogenous noradrenaline release in the rat cerebral cortex in vivo by transcortical dialysis: effects of drugs affecting noradrenergic neurotransmission. J Neurochem 46: 1794-1801.

Marrosu F, Fornal CA, Metzler CW, Jacobs BL (1996). 5-HT1A agonists induce hippocampal theta activity in freely moving cats: role of presynaptic 5-HT1A receptors. Brain Res 739: 192-200.

Millan MJ, Gobert A, Lejeune F, Newman-Tancredi A, Rivet JM, Auclair A et al (2001). S33005, a novel ligand at both serotonin and norepinephrine transporters: I. Receptor binding, electrophysiological, and neurochemical profile in comparison with venlafaxine, reboxetine, citalopram, and clomipramine. J Pharmacol Exp Ther 298: 565-580.

Nestler EJ, Barrot M, DiLeone RJ, Eisch AJ, Gold SJ, Monteggia LM (2002). Neurobiology of depression. Neuron 34: 13-25.

Orban G, Kiss T, Lengyel M, Erdi P (2001). Hippocampal rhythm generation: gamma-related theta-frequency resonance in CA3 interneurons. Biol Cybern 84: 123-132.

Parra P, Gulyas AI, Miles R (1998). How many subtypes of inhibitory cells in the hippocampus? Neuron 20: 983-993.

Penttonen M, Kamondi A, Acsady L, Buzsaki G (1998). Gamma frequency oscillation in the hippocampus of the rat: intracellular analysis in vivo. Eur J Neurosci 10: 718-728. 
Perry KW, Fuller RW (1997). Fluoxetine increases norepinephrine release in rat hypothalamus as measured by tissue levels of MHPG-SO ${ }_{4}$ and microdialysis in conscious rats. J Neural Transm 104: 953-966.

Raghavachari S, Kahana MJ, Rizzuto DS, Caplan JB, Kirschen MP, Bourgeois B et al (2001). Gating of human theta oscillations by a working memory task. J Neurosci 21: 3175-3183.

Rammsayer TH, Hennig J, Haag A, Lange N (2001). Effects of noradrenergic activity on temporal information processing in humans. Q J Exp Psychol B 54: 247-258.

Sacchetti G, Bernini M, Bianchetti A, Parini S, Invernizzi RW, Samanin R (1999). Studies on the acute and chronic effects of reboxetine on extracellular noradrenaline and other monoamines in the rat brain. Br J Pharmacol 128: 13321338.

Sapolsky RM (2000). The possibility of neurotoxicity in the hippocampus in major depression: a primer on neuron death. Biol Psychiatry 48: 755-765.

Seager MA, Johnson LD, Chabot ES, Asaka Y, Berry SD (2002). Oscillatory brain states and learning: Impact of hippocampal theta-contingent training. Proc Natl Acad Sci USA 99: $1616-1620$.
Sheline Y, Wang P, Gado M, Csernansky J, Vannier M (1996). Hippocampal atrophy in recurrent major depression. Proc Natl Acad Sci USA 93: 3908-4003.

Siepmann M, Muck-Weymann M, Joraschky P, Kirch W (2001). The effects of reboxetine on autonomic and cognitive functions in healthy volunteers. Psychopharmacology (Berl) 157: 202-207.

Tanum L (2000). Reboxetine: tolerability and safety profile in patients with major depression. Acta Psychiatr Scand 402(Suppl): 37-40.

Traub RD, Whittington MA, Colling SB, Buzsaki G, Jefferys JG (1996). Analysis of gamma rhythms in the rat hippocampus in vitro and in vivo. J Physiol 493: 471-484.

Vertes RP, Kocsis B (1997). Brainstem-diencephalo-septohippocampal systems controlling the theta rhythm of the hippocampus. Neuroscience 81: 893-926.

Whittington MA, Faulkner HJ, Doheny HC, Traub RD (2000). Neuronal fast oscillations as a target site for psychoactive drugs. Pharmacol Ther 86: 171-190.

Wong EH, Sonders MS, Amara SG, Tinholt PM, Piercey MF, Hoffmann WP et al (2000). Reboxetine: a pharmacologically potent, selective, and specific norepinephrine reuptake inhibitor. Biol Psychiatry 47: 818-829. 